\title{
Comparative study on mid- and long-term clinical effects of medial pivot prosthesis and posterior-stabilized prosthesis after total knee arthroplasty
}

Weipeng Shi ${ }^{1,2+}$, Yaping Jiang ${ }^{3 \dagger}$, Changyao Wang ${ }^{1}$, Haining Zhang ${ }^{1}$, Yingzhen Wang ${ }^{1 *+}$ and Tao $\mathrm{Li}^{1{ }^{*+}}$ (D)

\begin{abstract}
Objective: The purpose of this study was to explore the mid-and long-term clinical effects of Chinese patients with medial pivot (MP) prosthesis and posterior-stabilized (PS) prosthesis after total knee arthroplasty (TKA), to provide a reference for the recommendation of clinical prostheses.

Methods: A retrospective analysis of 802 patients who received TKA was performed from June 2010 to December 2013. A total of 432 patients received a MP prosthesis (MP group) and 375 patients received a PS prosthesis (PS group). Postoperative range of motion (ROM), clinical scores including the knee scoring system (KSS), the Western Ontario and McMaster Universities osteoarthritis index (WOMAC), the forgotten joint score (FJS), and postoperative complications were compared between the two groups.

Results: A total of 527 patients were followed up, including 290 in the MP group and 237 in the PS group. Both groups achieved satisfactory results in terms of KSS score, WOMAC score, and postoperative ROM, which were significantly improved compared with those before surgery, but the difference between the groups was not statistically significant $(P>0.05)$. The FJS scores of the MP group and the PS group were satisfactory and no significant difference was observed $(P=0.426)$. Postoperative complications occurred in 5 and 11 patients in the MP group and PS group, respectively.

Conclusion: The clinical results of TKA with MP or PS in Chinese patients at mid- and long-term are encouraging, and no significant differences were observed between the two types of prostheses. Studies have also shown that both prostheses are safe for Chinese patients.
\end{abstract}

Keywords: Medial pivot prosthesis, Posterior-stabilized prosthesis, Total knee arthroplasty, Mid- and long-term, Clinical effect

\footnotetext{
* Correspondence: 421633233@qq.com; huangyuanlanglitao@163.com

'Weipeng Shi and Yaping Jiang, Yingzhen Wang and Tao Li contributed equally to this work.

'Department of Joint Surgery, The Affiliated Hospital of Qingdao University, No. 59, Haier Road, Qingdao 266000, China

Full list of author information is available at the end of the article
}

(c) The Author(s). 2020 Open Access This article is licensed under a Creative Commons Attribution 4.0 International License, which permits use, sharing, adaptation, distribution and reproduction in any medium or format, as long as you give appropriate credit to the original author(s) and the source, provide a link to the Creative Commons licence, and indicate if changes were made. The images or other third party material in this article are included in the article's Creative Commons licence, unless indicated otherwise in a credit line to the material. If material is not included in the article's Creative Commons licence and your intended use is not permitted by statutory regulation or exceeds the permitted use, you will need to obtain permission directly from the copyright holder. To view a copy of this licence, visit http://creativecommons.org/licenses/by/4.0/. The Creative Commons Public Domain Dedication waiver (http://creativecommons.org/publicdomain/zero/1.0/) applies to the data made available in this article, unless otherwise stated in a credit line to the data. 


\section{Introduction}

With the development of the aging population, knee joint degenerative disease has become a global common condition of the elderly. At present, total knee arthroplasty (TKA) is the first choice for the treatment of endstage osteoarthrosis [1, 2]. The first-generation knee prosthesis was designed and developed by Gonston et al. in 1969 [3]. After increased development and improvement, present-day knee joint prostheses can better restore the natural kinematics of the knee joint and have improved the survival rates.

Posterior-stabilized (PS) prosthesis is a classic clinical prosthesis, which has the advantages of a clear incision exposure, a simple soft-tissue balance, and a greater range of motion (ROM) of the knee joint [4]. It relies on the femoral cam to improve the rollback, improves the stability of knee joint movement and motion translation, and prevents posterior subluxation [5]. However, the structure of the cam post may impact the central post, cause patella slip syndrome, and the extent of the osteotomy is large, which introduces difficulties for subsequent revision surgery [6].

During knee flexion, the contact points of the medial tibiofemoral articular surface are used as the axis, and the tibia is rotated in relation to the femur [7-9]. According to the characteristics of knee kinematics, the medial pivot (MP) prosthesis, which adopts the concept of the "ball-and-socket" design, has been developed. The medial part of the high molecular polyethylene gasket has the shape of a "ball-and-socket" unit, which limits anterior and posterior movement of the medial condyle of the femur, while the lateral condyle can achieve normal back-rolling movement during knee flexion [4, 1013]. The MP prosthesis with a single radius of curvature has the advantages of maximizing the ROM of the joint and the contact area between the polyethylene gasket and the femoral prosthesis. This will reduce the wear of the gasket, thereby increasing joint stability and improving the patella trajectory through the "ball-and-socket" model [14-16].

However, due to differences in anatomical structure between the Asian and European population, postoperative knee pain, limited mobility, and joint instability often occur [17-19], and there are very little experimental data obtained from Chinese people. The purpose of this study was to compare mid- and long-term clinical effects of TKA with MP and PS prostheses to provide a reference for the clinical selection of prostheses in Chinese patients.

\section{Materials and methods}

From June 2010 to December 2013, a retrospective study of patients undergoing TKA at the Department of Joint Surgery, the Affiliated Hospital of Qingdao University
(Qingdao, China) was conducted. All included patients were diagnosed with knee osteoarthropathy. Patients were excluded if they had a BMI $35 \mathrm{~kg} / \mathrm{m}^{2}$, suffered from cardio-cerebral vascular, neurological, and mental related system diseases, or had previous fractures around the knee joint. Patients who received other surgical treatments, such as high tibial osteotomy, patients who intended to undergo knee revision surgery, or patients whose daily lives were severely affected due to reasons other than knee surgery, were not included in this study.

In this study, MP (Advance Medial-Pivot Knee System, Wright Medical Group) or PS prosthesis (NexGen LPSFlex, Zimmer, Warsaw, IN) were adopted. Patients were placed into the supine position, with general anesthesia and a nerve block being used before surgery, and electric pneumatic hemostat as well as $300 \mathrm{mmHg}$ pressure was used at the start of surgery. An anterior median and longitudinal incision of the knee joint was created, and the paracondylar approach was used to remove the synovium, part of the fat pad, the meniscus, the anterior cruciate ligament, and osteophytes. The femoral side was positioned intramedullary, the distal femur at valgus $5^{\circ}$ (PS prosthesis $6^{\circ}$ ), the tibial side was placed extramedullary, and the posterior incline was $3^{\circ}$ (PS prosthesis $7^{\circ}$ ). The patella was trimmed, and the local anesthetic was injected into the surrounding tissue and posterior articular capsule before the prosthesis was placed. Tranexamic acid was injected into the articular cavity before suturing the subcutaneous tissue and a drainage tube was inserted.

By searching the electronic medical record system of the Affiliated Hospital of Qingdao University (Qingdao, China), data on the knee movements of patients before surgery were obtained, and all data obtained after surgery were measured by specialists in joint surgery. The patient was placed in a supine position, and the knee joint was straightened and flexed as much as the patient tolerated. Extension and flexion angles were recorded. For each patient, the measurement was performed in triplicate, and the final angle was averaged. The KSS score scale is divided into two parts: the clinical and the functional score, with the total score of both parts being 100 points. Scores greater than 85 points are considered excellent, 70-84 points are good, 60-69 points are acceptable, and scores less than 60 points are considered poor. Responses on the WOMAC scoring scale can be rated as "no difficulty," "slight difficulty," "medium difficulty," "very difficult," or "extremely difficult," with a score of 0-4 points, and the total score is the sum of the individual scores. The FJS score is a scale for evaluating a patients' post-operative satisfaction. It includes 12 questions with five possible answers for each question. A high total score indicates a high degree of forgetting and a low score indicates a low degree of forgetting. 
Complications mainly include pain in the anterior knee area, loss of sensation around the knee joint incision, knee snapping and poor healing of the incision, fracture around the prosthesis, loosening of the prosthesis, biomechanical instability of the knee joint, infection around the prosthesis, and other related systemic complications.

The SPSS software (version 26.0) was used to analyze the collected data, which were tested by KolmogorovSmirnov test for normal distribution, $t$ test, non-uniform normal distribution, and non-parametric test. The chisquare test was used for comparison between groups, and the significance level was set at 0.05 .

\section{Results}

This study included 802 patients who met the inclusion criteria, and a total of 527 patients for whom follow-up data were available. In the MP group, 290 patients were followed up. The average age of the patients was 74.58 $( \pm 6.97)$ years, the average body mass index (BMI) was $27.89( \pm 3.65) \mathrm{kg} / \mathrm{m}^{2}$, and the average follow-up time was 81.04 ( \pm 7.66$)$ months. In the PS group, 237 patients were followed up. The average age of the patients was 75.84 ( \pm 5.70$)$ years, the body mass index (BMI) was $27.43( \pm 3.51) \mathrm{kg} / \mathrm{m}^{2}$, and the average follow-up time was $80.78( \pm 7.85)$ months. Both groups were balanced in their baseline characteristics (Table 1). Typical cases of MP prosthesis and PS prosthesis are presented in Figs. 1 and 2.

\section{Rom}

The average preoperative ROM was $89.79( \pm 12.00)$ in the MP group and 88.04 $( \pm 13.02)$ in the PS group. The postoperative ROM of the MP and PS groups were $113.72( \pm 8.43)$ and $112.72( \pm 8.18)$, respectively, with no significant difference between the two groups $(P=$ $0.253)$. The ROM of the MP group increased by $23.93( \pm$ 11.39 ) and the ROM of the PS group increased by 24.68 $( \pm 14.05)$ compared to before the operation. No significant differences were observed between the two groups $(P=0.978)($ Fig. 3$)$.

\section{KSS}

The clinical and functional scores of the KSS before surgery in the two groups were balanced $(P>0.05)$ (Table 1). Scores related to pain, stability, walking conditions, and up and down the stairs of the two groups of patients were significantly improved after surgery, but no significant differences were observed between the clinical and functional scores of KSS (Fig. 4).

\section{WOMAC}

Patients in the MP and PS groups had significantly lower postoperative WOMAC scores in terms of pain, stiffness/rigidity, and activity/daily life than before the surgery. Among them, the activity score improved the most, however, the differences between the WOMAC scores of the two groups was not statistically significant (Fig. 5).

\section{FJS}

The overall FJS score between the two groups was satisfactory, with an average of $68.89( \pm 25.04)$ in the MP group and $65.29( \pm 24.93)$ in the PS group. The degree of amnesia of the knee prosthesis in the MP group was slightly higher compared to that in the PS group, but no significant differences were observed in the FJS scores between the two groups $(P=0.426)$.

Table 1 Preoperative characteristics of patients with follow-up data

\begin{tabular}{|c|c|c|c|c|}
\hline & $M P^{b}$ group $(n=290)$ & $\mathrm{PS}^{\mathrm{C}}$ group $(n=237)$ & Statistics & $P$ values \\
\hline Gender (female) & $228(78.6 \%)$ & $169(71.3 \%)$ & 3.753 & 0.053 \\
\hline Age (year) & $74.5 \pm 6.97$ & $75.4 \pm 5.70$ & $31,359.500$ & 0.084 \\
\hline Body mass index $\left(\mathrm{kg} / \mathrm{m}^{2}\right)$ & $27.89 \pm 3.65$ & $27.43 \pm 3.51$ & 32585.000 & 0.306 \\
\hline Side (left) & $140(48.3 \%)$ & $110(46.4 \%)$ & 0.181 & 0.053 \\
\hline Length of follow-up (month) & $81.04 \pm 7.66$ & $80.78 \pm 7.85$ & $33,509.000$ & 0.622 \\
\hline $\mathrm{KSS}^{\mathrm{a}}$ clinical score & $40.76 \pm 10.00$ & $41.35 \pm 7.50$ & $33,675.500$ & 0.692 \\
\hline KSS function score & $41.00 \pm 11.44$ & $41.18 \pm 11.20$ & $34,013.000$ & 0.437 \\
\hline WOMAC $^{d}$ total score & $80.72 \pm 6.35$ & $80.04 \pm 7.09$ & $32,166.000$ & 0.206 \\
\hline WOMAC pain score & $15.00 \pm 3.23$ & $14.98 \pm 4.08$ & $34,117.500$ & 0.885 \\
\hline WOMAC rigidity score & $5.93 \pm 1.34$ & $5.92 \pm 1.65$ & $33,944.000$ & 0.800 \\
\hline WOMAC activity score & $59.19 \pm 6.35$ & $59.14 \pm 5.27$ & $32,054.500$ & 0.183 \\
\hline
\end{tabular}

Comparison of the main indicators of the two groups

${ }^{a} K S S$ knee scoring system

${ }^{\mathrm{b}} \mathrm{MP}$ medial pivot prosthesis

CPS posterior-stabilized prosthesis

${ }^{d}$ WOMAC the Western Ontario and McMaster Universities osteoarthritis index 

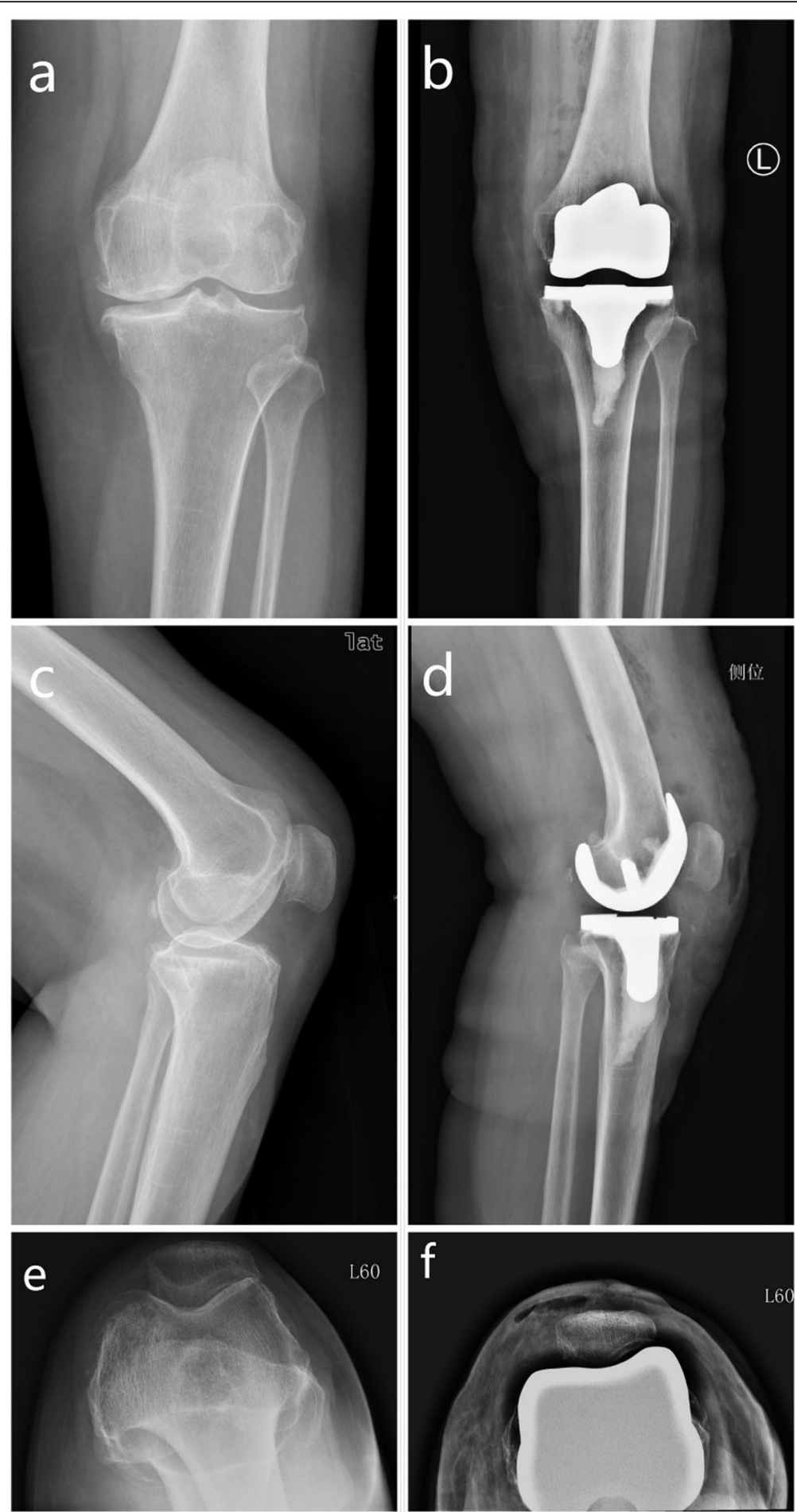

Fig. 1 Typical case of medial pivot prosthesis. a Anteroposterior position before surgery in patients with medial pivot (MP) prosthesis. b Anteroposterior position after surgery in patients with MP prosthesis. $\mathbf{c}$ Lateral position of the knee joint before surgery in patients with MP prosthesis. $\mathbf{d}$ Lateral position of the knee joint after surgery in patients with MP prosthesis. e Patella axial radiograph $\left(60^{\circ}\right)$ before surgery in patients with MP prosthesis. $\mathbf{f}$ Patella axial radiograph $\left(60^{\circ}\right)$ after surgery in patients with MP prosthesis 

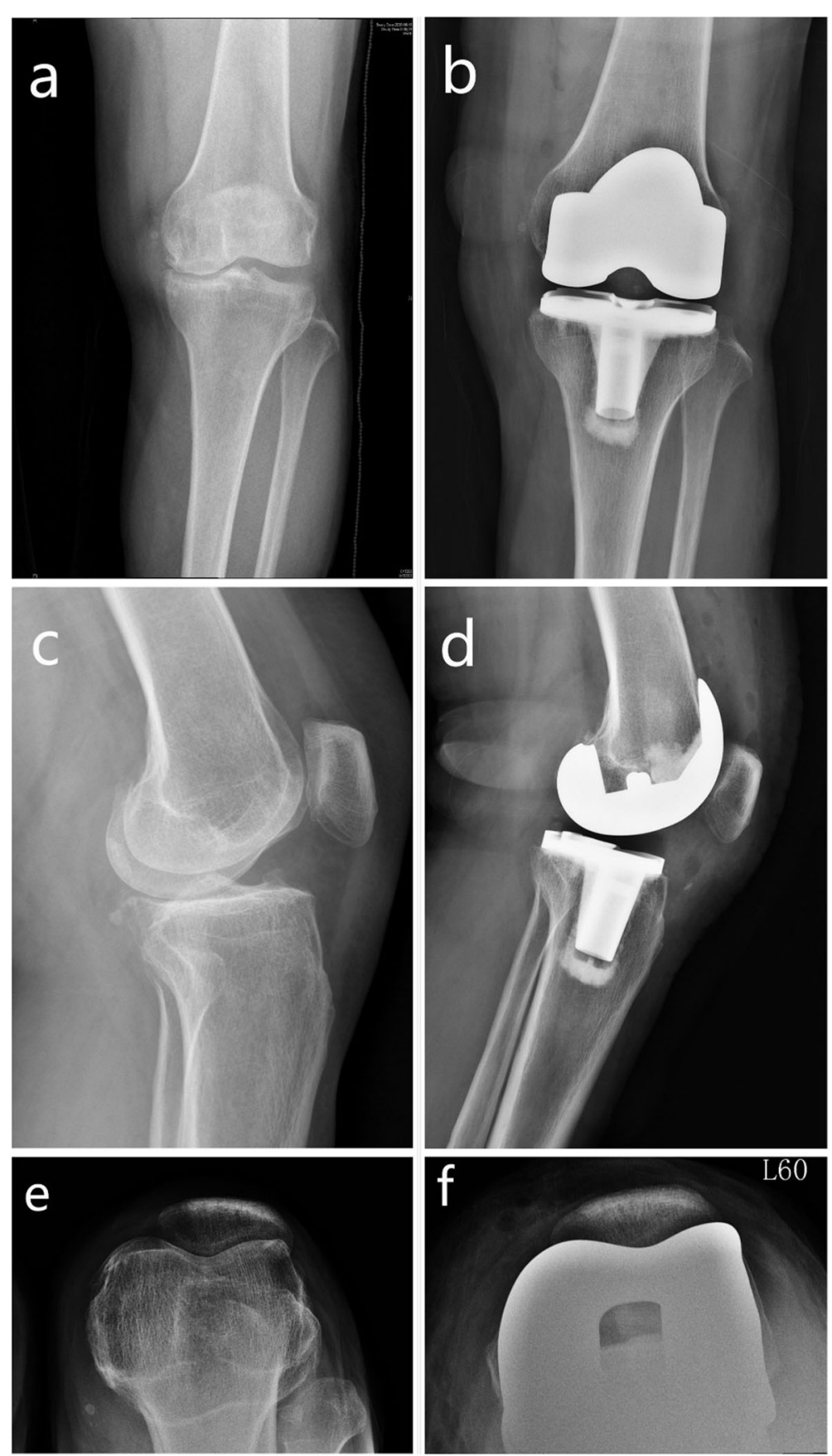

Fig. 2 Typical case of posterior-stabilized prosthesis. a Anteroposterior position before surgery in patients with posterior-stabilized (PS) prosthesis. b Anteroposterior position after surgery in patients with PS prosthesis. $\mathbf{c}$ Lateral position of the knee joint before surgery in patients with PS prosthesis. $\mathbf{d}$ Lateral position of the knee joint after surgery in patients with PS prosthesis. e Patella axial radiograph $\left(60^{\circ}\right)$ before surgery in patients with PS prosthesis. $\mathbf{f}$ Patella axial radiograph $\left(60^{\circ}\right)$ after surgery in patients with PS prosthesis

\section{Complications}

In the MP group, five patients experienced complications from the surgery. Two patients had a surgery-related infection, but this subsided after the second-stage revision. One patient experienced joint pain, which was treated by polyethylene gasket removal. One patient experienced numbness around the incision, and neurotrophic drugs was adopted. The patient still feels insensitive in certain areas around the knee. During the recovery phase, in one patient, the incision was not healed 2 weeks after surgery. Finally, it was healed through multiple surgical dressings. In the PS group, a total of 11 patients showed 


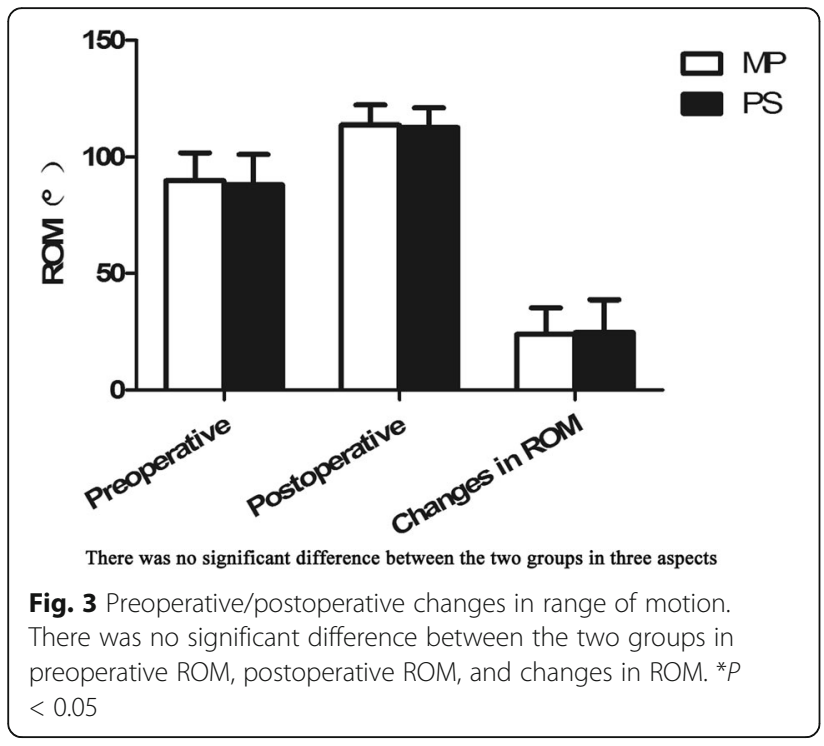

complications, one person had an infection after surgery but recovered after the two-stage revision, and three people presented with pain in the anterior knee area during postoperative activities, which gradually disappeared after oral administration of non-steroidal antiinflammatory drugs. The knee joint of five patients clicked slightly, and two patients presented with numbness around the incision, which did not affect daily life; hence, no targeted treatment was given. No systemic complications, such as deep vein thrombosis or pneumonia in the lower extremities were observed.

\section{Discussion}

This study aimed to explore the clinical results of Chinese patients who underwent implantation of MP and PS prostheses for TKA at mid- to long-term follow-

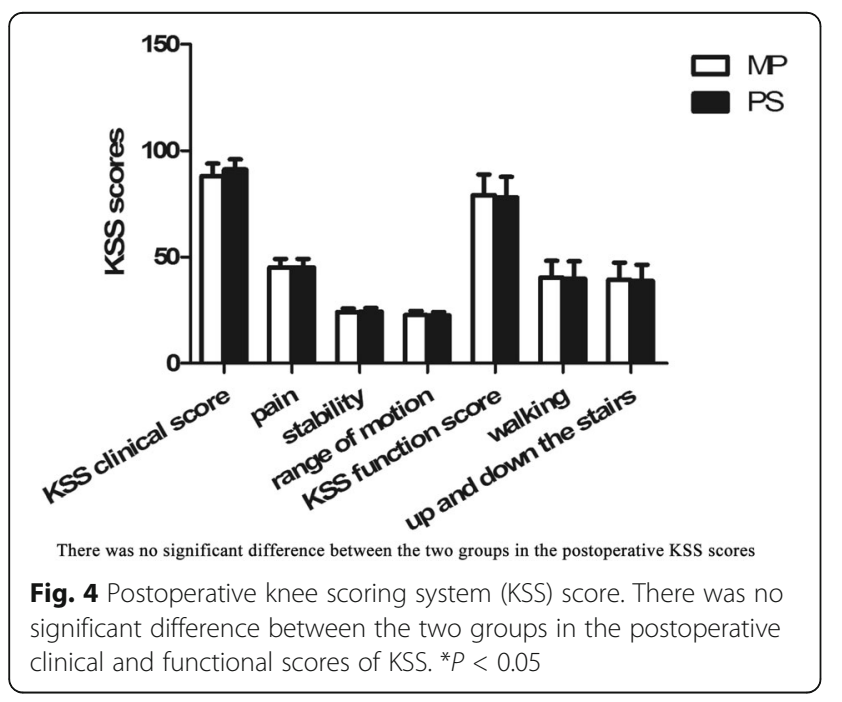

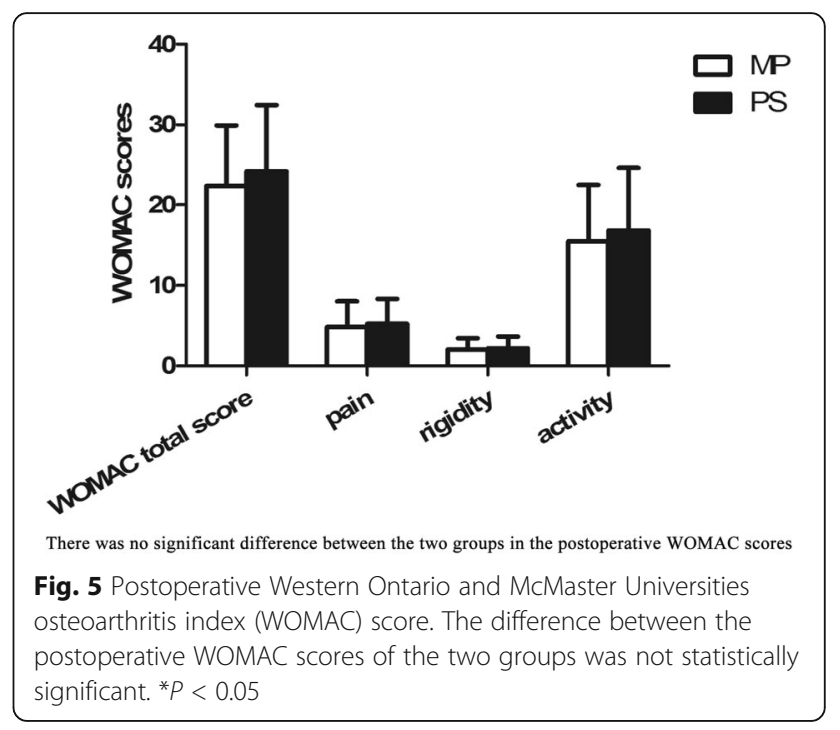

up. We found that MP and PS prostheses have similar clinical effects mid- to long-term, both for knee function and ROM. This overall effect was consistent with the findings presented in previous studies, which showed that MP prostheses can achieve satisfactory results in clinical and imaging studies at mid- to long-term follow-up [4, 8, 20-22]. Chinzei et al. [20] found that the success rate of the MP prosthesis was 98.3\% during an 8-year follow-up of 76 patients (85 knees), however, only one case of infectious loosening occurred. The survival rate of the prosthesis in the study of Dehl et al. [21] reached 95.9\%, and no aseptic loosening was observed. In the present study, two cases in the MP group presented with an infection around the prosthesis after surgery, which was successfully treated after the second-stage revision, and one case was treated after removal of the polyethylene gasket due to joint pain. There was one case of joint infection in PS group, which was adequately treated after the second-stage revision. The 6.5-year survival rate of the PS prosthesis was about $99.6 \%$. In the PS group, there was one infection, which was recovered after a second-stage revision. The infection rates of the MP and PS groups were $0.7 \%$ and $0.4 \%$, respectively, which were similar to the results presented in the previous studies [23]. In this study, the 6.5-year survival rate of the MP prosthesis was slightly lower than that of the PS group. It cannot be ruled out that there may be data deviations caused by various factors, such as revisions or surgical techniques in missing patients. Compared with the PS prosthesis, the MP prosthesis produced smaller, rounder, and fewer particles, which may have a smaller effect on osteolysis and aseptic loosening [24], making the MP prosthesis more ideal in terms of the survival rate. 
In this study, no significant differences in both the postoperative ROM and ROM increase were observed between the two groups, which was similar to the findings presented in the previous studies [25, 26]. Although the MP prosthesis may have advantages over the PS prosthesis in kinematics and contact area, no significant differences were observed between the two groups in terms of postoperative flexion. David et al. [4] found that the MP prosthesis had a better postoperative flexion than the PS prosthesis (MP group $120.3^{\circ}$ vs PS group $\left.112.8^{\circ}\right)$. In only a few studies, it was shown that the postoperative flexion of the MP prosthesis can reach more than $120^{\circ}$, for example, in a study by Bae et al. [26], 150 patients with an MP prosthesis were followed up for 5 years, and it was found that the average postoperative flexion can reach $124^{\circ}$, which may be related to the preoperative flexion, reaching more than $120^{\circ}$. However, the follow-up of 92 patients by Kim et al. [27] for 2.6 years showed that the early clinical effect of MP prosthesis was worse with a smaller ROM, poor patient satisfaction, and higher incidence of complications.

In this study, both MP and PS groups showed a significant improvement in the KSS scores compared to the scores before surgery, which was similar to the results previously reported $[20,26,28]$. The rates of the postoperative KSS clinical score in both groups reached $100 \%$, and the rates of KSS functional score were $86.8 \%$ and $86.9 \%$, in MP and PS groups, respectively, which may be related to a more subjective index items in the functional score. In the WOMAC score, the two groups of patients also improved significantly, but there was no significant difference between groups. At present, there are a few studies on the use of the FJS, which has the advantages of a tool with high structural validity and high reliability for repeated testing, with the upper limit effect of the FJS being lower compared to WOMAC. In previous studies, patients in the MP group had a higher final FJS score than the PS group [4, 29], because a high degree of stability is required when the knee joint is straightened from the flexion state. In contrast, the cam mechanism of the PS prosthesis will produce higher contact stress, which leads to knee instability, thereby affecting the ability of the knee joint to change from high flexion to straight extension [30]. Therefore, the FJS score in the PS group was lower than that in the MP group.

Current research suggests that skin numbness and paresthesia after TKA are mainly caused by cutaneous nerve injury close to the anterior knee incision [31]. The peripheral nerve distribution of the knee joint is divided into shallow and deep layers. The shallow layer comprises the cutaneous nerve, and the deep layer is composed of the joint capsule, the surrounding ligaments, and the arterial branches that are connected to the joint.
Clinically, the classic approach of anterior midline incision of the knee joint is mostly used, therefore, it is inevitable that the cutaneous nerve in front of the knee joint is cut, resulting in numbness of the skin around the cut after the artificial TKA. In the present study, one patient in the MP group and two in the PS group experienced numbness around the incision, because the surgery was carried out by creating a mid-knee incision, resulting in a lack of sensation due to damaged cutaneous nerves. The affected patients received neurotrophic drugs for conservative treatment, but in most cases, partial sensory deficits remained.

Pain in the anterior knee is a major factor affecting the quality of life of patients after TKA. It can be caused by dysfunction of the patellofemoral joint in the anterior knee region, abnormalities in the patellar trajectory, and high contact stress of the patellofemoral joint after surgery [32]. In previous studies, it was shown that pain in the anterior knee area was closely related to the type of prosthesis [33, 34]. The PS prosthesis requires an intercondylar box to accommodate the column, and when the knee joint changes from flexion to extension, the patella will touch the intercondylar box. The long-term consequences of this constellation are hyperplasia of the fibrous tissue nodules, which get in contact with the intercondylar box of the PS prosthesis, and cause pain in the anterior part of the knee during the extension to $30-40^{\circ}[35,36]$. In the present study, three patients in the PS group developed pain in the anterior knee area. After continued oral administration of nonsteroidal antiinflammatory analgesics for 2 months, the symptoms gradually disappeared, without adversely affecting postoperative functional recovery.

Clinically, the phenomenon of joint popping or a clicking sound after knee arthroplasty is quite common. The main reason is that small nodules of the fibrous synovial hyperplasia at the superior junction of the quadriceps tendon and patella are stuck in the intercondylar fossa during movement of the knee joint. The box restricts the upward movement of the patella. When the small nodule pops out of the intercondylar box, the patella suddenly moves upwards and produces a snapping sound [37, 38]. Hozack coined this phenomenon the patellar clunk syndrome, which may be related to an abnormal patella trajectory and the type of prosthesis [38-42]. The average time for the clicking sound to occur for the first time is 5 to 11 months [43]; however, it has also been reported that it can occur up to 6 years after surgery [44] and generally requires surgery to be removed. Anderson et al. [17] pointed out that because of the improvement of the MP prosthesis biomechanically, it does not require an intercondylar box to accommodate the post, which can extend the pulley groove downward so that the patella does not leave the femoral 
pulley during extension and flexion, thereby reducing the occurrence of patellar and postoperative patellofemoral joint complications from 25 to $0 \%$ in the PS group. In the MP group, no postoperative clicking sound was observed, while five patients with slight clicking presented in the PS group, which occurred mainly during the process of knee joint flexion to extension. We suspect that it may be caused by hyperplastic nodules that are stuck in the intercondylar box. Because these patients felt it did not affect their daily life, they were not given targeted diagnosis and treatment.

In summary, despite the high loss to follow-up rate in this study, no significant differences were observed between the two types of prostheses in terms of postoperative clinical effects, infection rates, and prosthesis survival rate in Chinese patients. The overall improvement is encouraging in at mid- and long-term follow-up after surgery, and patient satisfaction is high. The incidence of postoperative complications in general is lower than the overall level, which shows that the two types of prostheses are safe and reliable.

\section{Conclusion}

The clinical results of knee arthroplasty with MP or PS in Chinese patients at mid- and long-term follow-up are encouraging, with no significant differences observed between the two types of prostheses. Studies have also shown that both prostheses are safe for Chinese patients.

\section{Acknowledgements}

None

\section{Authors' contributions}

TL and YZW designed the study. WPS and YPJ analyzed the data and wrote the original manuscript. CYW and HNZ participated in the design of the study. The co-authors read and authorized the final manuscript for publication. All author(s) read and approved the final version of the manuscript.

\section{Funding}

National Natural Science Foundation of China, Grant number: 81802151; Shandong Province Natural Science Foundation, Grant number: ZR2019MH012; China Postdoctoral Science Foundation, Grant number: 2018 M642616; Qingdao Applied Foundational Research Youth Project, Grant number: 19-6-2-55-cg.

\section{Availability of data and materials}

All data are contained in the text and charts of published articles.

\section{Ethics approval and consent to participate}

This study is a retrospective study, so no informed consent is required.

\section{Consent for publication}

The co-authors agreed on the final version of the manuscript.

\section{Competing interests}

The authors declare that they have no competing interests.

\section{Author details}

'Department of Joint Surgery, The Affiliated Hospital of Qingdao University, No. 59, Haier Road, Qingdao 266000, China. ${ }^{2}$ Medical Department of Qingdao University, Qingdao 266071, Shandong, China. ${ }^{3}$ Department of Oral
Implantology, The Affiliated Hospital of Qingdao University, Qingdao 266003, China.

Received: 3 July 2020 Accepted: 9 September 2020

Published online: 17 September 2020

\section{References}

1. Husted RS, Wilquin L, Jakobsen TL, Holsgaard-Larsen A, Bandholm T. Rapid knee-extensions to increase quadriceps muscle activity in patients with total knee arthroplasty: a randomized cross-over study. Int J Sports Phys Ther. 2017:12(1):105-16.

2. Roberto C, Christian C, Fabrizio M, Cozzi LA, Luigi S, Massimo I. The survival of total knee arthroplasty: current data from registries on tribology: review article. HSS J. 2017;13(1):28-31. https://doi.org/10.1007/s11420-016-9513-9.

3. Cien AJ, Penny PC, Horn BJ, Popovich JM, Taunt CJ. Comparison between liposomal bupivacaine and femoral nerve block in patients undergoing primary total knee arthroplasty. J Surg Orthop Adv. 2015;24(4):225-9.

4. Samy David A, Wolfstadt Jesse I, Iman V, Backstein DJ. A retrospective comparison of a medial pivot and posterior-stabilized total knee arthroplasty with respect to patient-reported and radiographic outcomes. J Arthroplast. 2018;33(5):1379-83. https://doi.org/10.1016/j.arth.2017.11.049.

5. Jacobs Wilco $\mathrm{CH}$, Clement Darren J, Wymenga $A B$. Retention versus removal of the posterior cruciate ligament in total knee replacement: a systematic literature review within the Cochrane framework. Acta Orthop. 2005;76(6): 757-68. https://doi.org/10.1080/17453670510045345.

6. Huten D. Femorotibial bone loss during revision total knee arthroplasty. Orthop Traumatol Surg Res. 2013;99(1 Suppl):S22-33. https://doi.org/10. 1016/j.otsr.2012.11.009.

7. Hill PF, Vedi V, Williams A, Iwaki H, Pinskerova V, Freeman MA. Tibiofemoral movement 2: the loaded and unloaded living knee studied by MRI. J Bone Joint Surg (Br). 2000;82(8):1196-8. https://doi.org/10.1302/0301-620X.82B8. 0821196.

8. Iwaki H, Pinskerova V, Freeman MA. Tibiofemoral movement 1: the shapes and relative movements of the femur and tibia in the unloaded cadaver knee. J Bone Joint Surg (Br). 2000;82(8):1189-95. https://doi.org/10.1302/ 0301-620X.82B8.0821189.

9. Nakagawa S, Kadoya Y, Todo S, Kobayashi A, Sakamoto H, Freeman MA, et al. Tibiofemoral movement 3: full flexion in the living knee studied by MRI. J Bone Joint Surg (Br). 2000;82(8):1199-200. https://doi.org/10.1302/ 0301-620X.82B8.0821199.

10. Fitch DA, Sedacki K, Yang Y. Mid- to long-term outcomes of a medial-pivot system for primary total knee replacement: a systematic review and metaanalysis. Bone Joint Res. 2014;3(10):297-304. https://doi.org/10.1302/20463758.310.2000290

11. Causero A, Di Benedetto P, Beltrame A, Gisonni R, Cainero V, Pagano M. Design evolution in total knee replacement: which is the future? Acta Biomed. 2014;85(Suppl 2):5-19 Published 2014 Sep 24.

12. Warth Lucian C, Ishmael Marshall K, Deckard Evan R, Mary Z-D, Michael MR. Do medial pivot kinematics correlate with patient-reported outcomes after total knee arthroplasty? J Arthroplast. 2017;32(8):2411-6. https://doi.org/10. 1016/j.arth.2017.03.019

13. Carvalho Júnior LH, Teixeira BP, Bernardes CO, Soares LF, Gonçalves MB, Temponi EF. Range of motion predictability after total knee arthroplasty with medial pivot prosthesis. Rev Bras Ortop. 2017;52(2):197-202Published 2017 Mar 9. https://doi.org/10.1016/j.rboe.2017.03.001.

14. Yuan D, Zhang QS, Zhang K, et al. Total knee arthroplasty using a medial pivot or posterior cruciate-stabilizing prosthesis in Chinese patients [published online ahead of print, 2019 may 7]. J Knee Surg. 2019;33(9):8928. https://doi.org/10.1055/s-0039-1688784.

15. Alexander G, Christian S, Matthias W, Peter M, Volkmar J, Arnd S. Medial stabilized and posterior stabilized TKA affect patellofemoral kinematics and retropatellar pressure distribution differently. Knee Surg Sports Traumatol Arthrosc. 2018;26(6):1743-50. https://doi.org/10.1007/s00167-017-4772-7.

16. Macheras George A, Galanakos Spyridon P, Panagiotis L, Anastasopoulos Panagiotis P, Papadakis SA. A long term clinical outcome of the medial pivot knee arthroplasty system. Knee. 2017;24(2):447-53. https://doi.org/10. 1016/j.knee.2017.01.008.

17. Anderson Michael J, Becker David L, Travis K. Patellofemoral complications after posterior-stabilized total knee arthroplasty: a comparison of 2 different implant designs. J Arthroplast. 2002;17(4):422-6. https://doi.org/10.1016/j. knee.2017.01.008. 
18. Nutton RW, Wade FA, Coutts FJ, van der Linden ML. Short term recovery of function following total knee arthroplasty: a randomised study of the medial parapatellar and midvastus approaches. Arthritis. 2014;2014:173857. https://doi.org/10.1155/2014/173857.

19. Zhou X, Tang J, Wu J, Zhang J, Zhou Y. Role of sliding osteotomy of lateral femur condyle in correcting severe fixed valgus deformity in total knee arthroplasty. Zhonghua Yi Xue Za Zhi. 2014;94(25):1963-5.

20. Nobuaki C, Kazunari I, Nobuhiro T, Tomoyuki M, Atsushi K, Tetsuhiro I, et al. Satisfactory results at 8 years mean follow-up after ADVANCE $^{\circledast}$ medial-pivot total knee arthroplasty. Knee. 2014;21(2):387-90. https://doi.org/10.1016/j. knee.2013.10.005.

21. Dehl M, Bulaïd Y, Chelli M, Belhaouane R, Gabrion A, Havet E, et al. Total knee arthroplasty with the medial-pivot knee system: clinical and radiological outcomes at 9.5 years' mean follow-up. Orthop Traumatol Surg Res. 2018;104(2):185-91. https://doi.org/10.1016/j.otsr.2017.10.016.

22. Robert S, Steven O, David BJ, Angelia A, Fitch David A, Lowry BC. Midterm clinical and radiographic results of the medial pivot total knee system. Int Orthop. 2014;38(12):2495-8. https://doi.org/10.1007/s00264-014-2444-5.

23. Inacio $M$, Paxton $E$, Chen $Y$, et al. Leveraging electronic medical records for surveillance of surgical site infection in a total joint replacement population. Infect Control Hosp Epidemiol. 2011;32(4):351-9. https://doi.org/10.1086/658942.

24. Minoda $Y$, Kobayashi A, Iwaki $H$, et al. Polyethylene wear particles in synovial fluid after total knee arthroplasty. Clin Orthop Relat Res. 2003;410:165-72. https://doi.org/10.1097/01.blo.0000063122.39522.c2.

25. Shakespeare D, Ledger M, Kinzel V. Flexion after total knee replacement. A comparison between the medial pivot knee and a posterior stabilised implant. Knee. 2006;13(5):371-3. https://doi.org/10.1016/j.knee.2006.05.007.

26. Kyung BD, Do CS, Kyu IS, Jun SS. Comparison of midterm clinical and radiographic results between total knee arthroplasties using medial pivot and posterior-stabilized prosthesis-a matched pair analysis. J Arthroplast. 2016;31(2):419-24. https://doi.org/10.1016/j.arth.2015.09.038

27. Young-Hoo K, Sung-Hwan Y, Jun-Shik K. Early outcome of TKA with a medial pivot fixed-bearing prosthesis is worse than with a PFC mobilebearing prosthesis. Clin Orthop Relat Res. 2009;467(2):493-503. https://doi. org/10.1007/s11999-008-0221-8

28. Cheng-Yu F, Tzung-Shian HJ, Ming-Shium $\mathrm{H}$, Ying-Chieh S, Lee C-H. Primitive results after medial-pivot knee arthroplasties: a minimum 5-year follow-up study. J Arthroplast. 2010;25(3):492-6. https://doi.org/10.1016/j. arth.2009.05.008

29. Fahad H, Shelain P, Shin-Jae R, Sami HF. Knee arthroplasty with a medially conforming ball-and-socket tibiofemoral articulation provides better function. Clin Orthop Relat Res. 2011;469(1):55-63. https://doi.org/10.1007/ s11999-010-1493-3.

30. Nakayama K, Matsuda S, Miura H, Iwamoto Y, Higaki H, Otsuka K. Contact stress at the post-cam mechanism in posterior-stabilised total knee arthroplasty. J Bone Joint Surg (Br). 2005;87(4):483-8. https://doi.org/10. 1302/0301-620X.87B4.15684.

31. Johnson DF, Love DT, Love BR, Lester DK. Dermal hypoesthesia after total knee arthroplasty. Am J Orthop (Belle Mead NJ). 2000;29(11):863-6.

32. Biedert RM, Sanchis-Alfonso V. Sources of anterior knee pain. Clin Sports Med. 2002;21(3):335-vii. https://doi.org/10.1016/s0278-5919(02)00026-1.

33. Wai-Pan Y, Wong Jimmy WK, Kwong-Yuen C, Tze-Pui N, Wai-Man T. Patellar clunk syndrome after posterior stabilized total knee arthroplasty. J Arthroplast. 2003;18(8):1023-8. https://doi.org/10.1016/S0883-5403(03)00447-9.

34. Vernace JV, Rothman $\mathrm{RH}$, Booth RE, Balderston RA. Arthroscopic management of the patellar clunk syndrome following posterior stabilized total knee arthroplasty. J Arthroplast. 1989;4(2):179-82. https://doi.org/10. 1016/S0883-5403(89)80072-5

35. Johnson DP. Midline or parapatellar incision for knee arthroplasty. A comparative study of wound viability. J Bone Joint Surg (Br). 1988;70(4):656-8.

36. Subramanian $S$, Lateef $H$, Massraf A. Cutaneous sensory loss following primary total knee arthroplasty. A two years follow-up study. Acta Orthop Belg. 2009;75(5):649-53.

37. Pollock David C, Ammeen Deborah J, Engh GA. Synovial entrapment: a complication of posterior stabilized total knee arthroplasty. J Bone Joint Surg Am. 2002;84(12):2174-8

38. Lonner JH, Jasko JG, Bezwada HP, Nazarian DG, Booth RE Jr. Incidence of patellar clunk with a modern posterior-stabilized knee design. Am J Orthop (Belle Mead NJ). 2007;36(10):550-3.

39. Park KK, Chang CB, Kang YG, Seong SC, Kim TK. Correlation of maximum flexion with clinical outcome after total knee replacement in Asian patients.
J Bone Joint Surg (Br). 2007;89(5):604-8. https://doi.org/10.1302/0301-620X. 89B5.18117.

40. Conrad David N, Dennis DA. Patellofemoral crepitus after total knee arthroplasty: etiology and preventive measures. Clin Orthop Surg. 2014;6(1): 9-19. https://doi.org/10.4055/cios.2014.6.1.9.

41. Ip D, Wu WC, Tsang WL. Comparison of two total knee prostheses on the incidence of patella clunk syndrome. Int Orthop. 2002;26(1):48-51. https:// doi.org/10.1007/s00264-001-0316-2.

42. Maloney WJ, Schmidt R, Sculco TP. Femoral component design and patellar clunk syndrome. Clin Orthop Relat Res. 2003;410:199-202. https://doi.org/10. 1097/01.blo.0000063606.67412.96.

43. Beight JL, Yao B, Hozack WJ, Hearn SL, Booth RE Jr. The patellar "clunk" syndrome after posterior stabilized total knee arthroplasty. Clin Orthop Relat Res. 1994;299:139-42.

44. Takahashi M, Miyamoto S, Nagano A. Arthroscopic treatment of soft-tissue impingement under the patella after total knee arthroplasty. Arthroscopy. 2002;18(4):E20. https://doi.org/10.1053/jars.2002.31968.

\section{Publisher's Note}

Springer Nature remains neutral with regard to jurisdictional claims in published maps and institutional affiliations.
Ready to submit your research? Choose BMC and benefit from:

- fast, convenient online submission

- thorough peer review by experienced researchers in your field

- rapid publication on acceptance

- support for research data, including large and complex data types

- gold Open Access which fosters wider collaboration and increased citations

- maximum visibility for your research: over $100 \mathrm{M}$ website views per year

At $\mathrm{BMC}$, research is always in progress.

Learn more biomedcentral.com/submissions 